\title{
Self-Healing and Damage Resilience for Soft Robotics: A Review
}

\author{
R. Adam Bilodeau ${ }^{1,2}$ and Rebecca K. Kramer ${ }^{1,2 *}$ \\ ${ }^{1}$ Purdue University, School of Mechanical Engineering, West Lafayette, IN, United States, ${ }^{2}$ Yale University, \\ School of Engineering and Applied Science, New Haven, CT, United States
}

\section{OPEN ACCESS}

Edited by:

Matteo Cianchetti,

Sant'Anna School of

Advanced Studies, Italy

Reviewed by:

Tommaso Ranzani,

Harvard University, United States

Ali Sadeghi,

Fondazione Istituto Italiano

di Technologia, Italy

*Correspondence:

Rebecca K. Kramer

rebecca.kramer@yale.edu

Specialty section:

This article was submitted

to Soft Robotics,

a section of the journal

Frontiers in Robotics and Al

Received: 20 June 2017 Accepted: 07 September 2017

Published: 03 October 2017

Citation:

Bilodeau RA and Kramer RK (2017) Self-Healing and Damage Resilience for Soft Robotics: A Review.

Front. Robot. Al 4:48.

doi: 10.3389/frobt.2017.00048
Advances in soft robotics will be crucial to the next generation of robot-human interfaces. Soft material systems embed safety at the material level, providing additional safeguards that will expedite their placement alongside humans and other biological systems. However, in order to function in unpredictable, uncontrolled environments alongside biological systems, soft robotic systems should be as robust in their ability to recover from damage as their biological counterparts. There exists a great deal of work on self-healing materials, particularly polymeric and elastomeric materials that can self-heal through a wide variety of tools and techniques. Fortunately, most emerging soft robotic systems are constructed from polymeric or elastomeric materials, so this work can be of immediate benefit to the soft robotics community. Though the field of soft robotics is still nascent as a whole, self-healing and damage resilient systems are beginning to be incorporated into three key support pillars that are enabling the future of soft robotics: actuators, structures, and sensors. This article reviews the state-of-the-art in damage resilience and self-healing materials and devices as applied to these three pillars. This review also discusses future applications for soft robots that incorporate self-healing capabilities.

Keywords: soft robotics, self-healing, damage resilience, soft actuators, soft sensors

\section{INTRODUCTION}

Soft robots are often inspired by key aspects of biological systems, such as their near-infinite degrees of freedom, dexterity, environmental adaptability, and power output (Kim et al., 2013; Rus and Tolley, 2015; Balasubramanian et al., 2016). Taking inspiration from the soft, deformable, and adaptable bodies found in nature, soft roboticists develop robotic systems with capabilities beyond those achievable by traditional rigid robots (Pfeifer et al., 2012; Majidi, 2013). Because of their materially soft nature, soft robotic technologies are often considered to be potentially safer for interaction with humans, both as human-assisting actuators and as wearable sensory skins (Hammock et al., 2013; Laschi and Cianchetti, 2014; Lu and Kim, 2014; Amjadi et al., 2016; Abidi and Cianchetti, 2017; Wang et al., 2017). However, in order to be commercially viable for everyday use in these applications, soft robots should be robust enough to function alongside their self-healing, damage resilient biological companions (Bauer et al., 2014).

This article reviews current examples of self-healing and damage resilient materials that have been integrated into soft robot technologies (actuation, structure, and electronics). This review also has the goal of showing that there is an open field of research in the future of self-healing, damage resilient soft robots. We exclude from this review the details of the chemistry behind self-healing materials, as many recent reviews and books are already dedicated to this subject 
(Wool, 2008; Wu et al., 2008; Ghosh, 2009; Hager et al., 2010, 2016; Murphy and Wudl, 2010; Ahner et al., 2015; Kuhl et al., 2015; Li and Meng, 2015; Roy et al., 2015; Huynh et al., 2017).

For the purpose of this article, we distinguish damage resistance from damage resilience. We define damage resistance as the ability to withstand an unexpected external stressor without damage, i.e., getting hit with a hammer, run over by a car, or exposed to open flame (Martinez et al., 2014; Tolley et al., 2014). Soft robots are almost always assumed to be damage resistant, an ideal characteristic for robots intended to function alongside biological systems in uncontrolled, unpredictable environments. We define damage resilience as the ability to be materially damaged (permanently deformed through crack propagation, fracture, mechanical failure, or puncture) and then continue functioning. Self-healing is an obvious subset of this overarching definition, yet it is a critical ability for next-generation soft robots and holds equal importance to general damage resilience. The idea that robots can self-heal, self-repair, or correct for damage that has occurred like biological systems is a concept that is still relatively new (Frei et al., 2013), but one that would continue to distinguish soft robots from their rigid-bodied counterparts (Bauer et al., 2014).

Among the many potential advantages of soft robotic systems is the opportunity to bypass functional partitions. While traditional robots are usually comprised of components with a single function (e.g., actuators, sensors, structures, and controllers), emerging multifunctional materials are enabling components that can fulfill two or three different functions simultaneously. In the sections that follow, we review the use of self-healing materials in soft actuators, soft structures, and soft sensing devices. However, we note that material systems often appear across these categories as researchers have solved different functional problems using the same materials. Table 1 provides a summary detailing some of the material applications and damage resilience systems presented in this review.

\section{DAMAGE RESILIENT AND SELF-HEALING SOFT ACTUATION}

Soft actuation comes in many forms, using specially designed material bodies or systems to convert an energy source into forces and displacements. Energy sources include (but are not limited to) electricity and electric fields, magnetic fields, pressurized gasses and liquids, thermal energy, and chemically induced mass transfer, each capable of providing kinematic motion (Madden et al., 2004; Hines et al., 2017). Though different in their underlying physics, soft actuators all allow for large strains (sometimes greater than 100\%) in a flexible or stretchable material. In this section, we look at the current research that has gone into making these actuators damage resilient.

\section{Dielectric Elastomer Actuators (DEAs)}

Dielectric elastomer actuators are a promising actuation mechanism for soft robots (Gu et al., 2017; Hines et al., 2017). DEAs are capable of high strain deformations at high frequencies $(<1 \mathrm{~s})$, reliable blocking forces, and rapid controllability, all of which are valuable qualities for actuation (Choi et al., 2007; Kofod, 2008; Kornbluh et al., 2009; Brochu and Pei, 2010; Anderson et al., 2012; Rosset and Shea, 2012; Carpi, 2016; Madsen et al., 2016a; Naficy et al., 2016). By sandwiching a highly stretchable dielectric layer between two stretchable electrodes, DEAs operate on a simple fundamental principle: charging the electrodes causes an attraction that squeezes the elastomer-based dielectric layer in between them, decreasing the actuator thickness and increasing its area. DEAs can be solid-state or semi-solid (where either the electrodes or the dielectric layer have fluidic elements), and their dielectrics can be made of silicones, acrylic elastomers, and other types of highly deformable, non-conductive materials (Romasanta et al., 2015). Very high electric potentials (in the range of $\mathrm{kV}$ ) are often necessary to induce significant shape change, despite the dielectric typically being a thin film $(<1 \mathrm{~mm})$. For greater details, the reader is recommended these recent reviews (Wang and Qu, 2016; Zhu et al., 2016; Zhang and Serpe, 2017).

The thin nature of DEAs makes them susceptible to defects from physical damage and manufacturing imperfections. These defects are often undetectable until the electric potential is applied (Zurlo et al., 2016), and they can create a continuous conductive bridge or a sudden spark between the electrodes, effectively ending the life of the actuator. Since this defect-induced failure occurs at potentials much lower than required for a general dielectric breakdown, the whole actuator is rendered useless by a single flaw. Identifying this critical issue with DEAs, researchers have begun to search in earnest for effective solutions.

\section{Fault-Tolerant Electrodes in DEAs}

Fault-tolerant DEAs are a subcategory of DEAs whose electrodes are resilient to damage caused by dielectric breakdown or puncture. The group led by Dr. Qibing Pei has been working for the past decade to develop "self-clearing" electrodes. They first demonstrated the basics of this idea in 2007 (Yuan et al., 2007), but it was not until their pioneering paper in 2008 that they showed that this type of fault-tolerant electrode could operate after damage, even with a solid foreign object piercing the entire actuator (Figure 1A) (Yuan et al., 2008). The researchers made a flexible, stretchable electrode from spray-coated single-walled carbon nanotubes (CNTs) that degrades locally around any spark caused by dielectric breakdown, outside sources of electricity, or physical piercing. This degradation breaks the local continuity, and therefore conductivity, of the electrode, preventing further loss of energy through the damaged area, though also locally increasing the stiffness of the electrode. Initial results demonstrated self-clearing damage resilient electrodes fabricated by spray-coating onto dielectrics made of acrylic elastomers, and further work demonstrated self-clearing CNT electrodes on silicone dielectric layers as well (Yuan et al., 2010). Silicone as the dielectric material enables tunability of the speed of the self-clearing response by changing the thickness of the dielectric layer. Furthermore, the self-clearing electrodes enhance the overall lifespan of a DEA, operating for tens of thousands of cycles while experiencing and overcoming periodic breakdowns during operation (Stoyanov et al., 2013).

Another research group led by Dr. Dorina Opris has investigated damage resilient DEAs, altering both the electrode 
TABLE 1 | Summary of self-healing and damage resilience mechanisms in the current soft robotic literature.

\begin{tabular}{|c|c|c|c|c|c|c|c|c|c|c|}
\hline $\begin{array}{l}\text { Damage } \\
\text { resilience } \\
\text { system }\end{array}$ & Application & Active material & $\begin{array}{l}\text { Modulus of } \\
\text { elasticity }\end{array}$ & $\begin{array}{l}\text { Damage } \\
\text { resilience } \\
\text { mechanism }\end{array}$ & $\begin{array}{l}\text { Self-healing } \\
\text { stimulus }\end{array}$ & $\begin{array}{l}\text { Recovery } \\
\text { time scale }\end{array}$ & $\begin{array}{l}\text { Recovered } \\
\text { material property }\end{array}$ & $\begin{array}{l}\text { Resilience } \\
\text { cycles }\end{array}$ & $\begin{array}{l}\text { Recovery } \\
\text { efficiency } \\
\text { per cycle }\end{array}$ & Reference \\
\hline \multirow[t]{2}{*}{$\begin{array}{l}\text { Damage } \\
\text { isolation }\end{array}$} & \multirow[t]{2}{*}{ Actuators (DEAs) } & Carbon nanotubes & $\mathrm{N} / \mathrm{A}$ & $\begin{array}{l}\text { Electrode } \\
\text { degradation }\end{array}$ & - & $0-10 s$ & Area strain & $>30$ & 0.99 & Stoyanov et al. (2013) \\
\hline & & Modified PMVS & $80-200 \mathrm{kPa}$ & $\begin{array}{l}\text { Dielectric } \\
\text { buffering }\end{array}$ & - & $0-10 s$ & Area strain & 5 & 0.99 & Dünki et al. (2015) \\
\hline \multirow[t]{2}{*}{$\begin{array}{l}\text { Material } \\
\text { elasticity }\end{array}$} & Actuators (inflatable) & $\begin{array}{l}\text { Kevlar/silicone } \\
\text { composite }\end{array}$ & $0.4 \mathrm{MPa}$ & $\begin{array}{l}\text { Elastomer } \\
\text { pressure }\end{array}$ & - & $0-10 s$ & Curvature change & 1 & - & Shepherd et al. (2013) \\
\hline & Electronics (RTLM) & Silicone (PDMS) & $1.84 \mathrm{MPa}$ & $\begin{array}{l}\text { Encapsulating } \\
\text { elastomer } \\
\text { pressure }\end{array}$ & - & $0-10 s$ & Conductivity & 2 & 0.99 & Li et al. (2016b) \\
\hline \multirow{5}{*}{$\begin{array}{l}\text { Physical self- } \\
\text { healing (fluidic } \\
\text { reflow) }\end{array}$} & \multirow[t]{2}{*}{ Actuators (DEAs) } & RTLM & $\mathrm{N} / \mathrm{A}$ & - & Applied voltage & $10-20 \mathrm{~s}$ & Area strain & 1 & 0.8 & Liu et al. (2013) \\
\hline & & Silicone oil & $\mathrm{N} / \mathrm{A}$ & - & $\begin{array}{l}\text { Voltage } \\
\text { reduction }\end{array}$ & $0-5 s$ & Area strain & 6 & 0.99 & Hunt et al. (2014) \\
\hline & \multirow[t]{2}{*}{$\begin{array}{l}\text { Structures (low melting } \\
\text { temperature materials) }\end{array}$} & $\begin{array}{l}\text { Low melting } \\
\text { temperature alloy }\end{array}$ & $9.25 \mathrm{GPa} / 0.54 \mathrm{MPa}$ & - & Joule heating & 5-10 min & Tensile strength & 3 & 0.78 & $\begin{array}{l}\text { Van Meerbeek } \\
\text { et al. (2016) }\end{array}$ \\
\hline & & Wax & $68-125 \mathrm{MPa}$ & - & Thermal & $10-20 \mathrm{~min}$ & Compressive strength & 2 & 0.9 & Cheng et al. (2014) \\
\hline & Electronics (RTLM) & RTLM & N/A & - & Thermal & $0-10 s$ & Conductivity & 2 & 0.99 & Li et al. (2016b) \\
\hline \multirow{12}{*}{$\begin{array}{l}\text { Chemical self- } \\
\text { healing (solid } \\
\text { bonding) }\end{array}$} & \multirow[t]{2}{*}{ Actuators (inflatable) } & S-H polymer & $7.85 \mathrm{MPa}$ & - & Thermal & $25 \mathrm{~h}$ & Contraction force & 3 & 0.98 & Terryn et al. (2017a) \\
\hline & & $\mathrm{S}-\mathrm{H}$ elastomers & $6-287 \mathrm{kPa}$ & - & UV & $30 \mathrm{~s}$ & Curvature change & 1 & 0.99 & Wallin et al. (2017) \\
\hline & Actuators (hydrogel) & S-H hydrogel & $240-770 \mathrm{kPa}$ & - & Thermal & $20 \mathrm{~min}$ & Tensile strength & 1 & 0.99 & Liu and Li (2017) \\
\hline & Actuators (DEAs) & S-H elastomer & $0.54 \mathrm{MPa}$ & - & Thermal & $72 \mathrm{~h}$ & Area strain & 1 & - & Li et al. (2016a) \\
\hline & \multirow{3}{*}{$\begin{array}{l}\text { Structure (shape memory } \\
\text { material) }\end{array}$} & \multirow{3}{*}{$\begin{array}{l}\text { Shape memory, } \\
\text { S-H polymer }\end{array}$} & $10-650 \mathrm{MPa}$ & \multirow[t]{3}{*}{-} & Thermal & $5 \mathrm{~h}$ & Bending load & 5 & 0.75 & Nji and Li (2012) \\
\hline & & & $0.3-0.4 \mathrm{MPa}$ & & Pressure & - & Curvature change & $>1$ & - & Huang et al. (2010) \\
\hline & & & & & Joule Heating & & & & & \\
\hline & \multirow[t]{2}{*}{ Electronics (RTLM) } & \multirow[t]{2}{*}{ S-H polymer } & \multirow[t]{2}{*}{$240 \mathrm{kPa}$} & \multirow[t]{2}{*}{-} & Thermal & $10-60 \mathrm{~min}$ & Conductivity & 1 & 0.75 & Palleau et al. (2013) \\
\hline & & & & & Pressure & & & & & \\
\hline & \multirow[t]{3}{*}{ Electronics (composites) } & \multirow[t]{2}{*}{ S-H elastomer } & \multirow[t]{2}{*}{$0.4-2 \mathrm{MPa}$} & \multirow[t]{2}{*}{-} & Thermal & $15-30 s$ & Conductivity & 3 & 0.98 & Tee et al. (2012) \\
\hline & & & & & Pressure & & & & & \\
\hline & & S-H hydrogel & $\begin{array}{c}0.67-0.8 \mathrm{MPa} \\
0.1 \mathrm{MPa} \\
0.1 \mathrm{MPa}\end{array}$ & - & Thermal & $\begin{array}{l}30-60 \mathrm{~s} \\
5 \mathrm{~min} \\
24 \mathrm{~h}\end{array}$ & $\begin{array}{l}\text { Conductivity } \\
\text { Conductivity } \\
\text { Fracture toughness }\end{array}$ & $\begin{array}{l}1 \\
1 \\
1\end{array}$ & $\begin{array}{l}0.96 \\
0.99 \\
0.95\end{array}$ & $\begin{array}{l}\text { Darabi et al. (2017) } \\
\text { Liu et al. (2017) } \\
\text { Cao et al. (2017b) }\end{array}$ \\
\hline
\end{tabular}

PDMS, polydimethyl siloxane; RTLM, room temperature liquid metal; S-H, self-healing; PMVS, polymethylvinylsiloxane; DEA, dielectric elastomer actuator. 


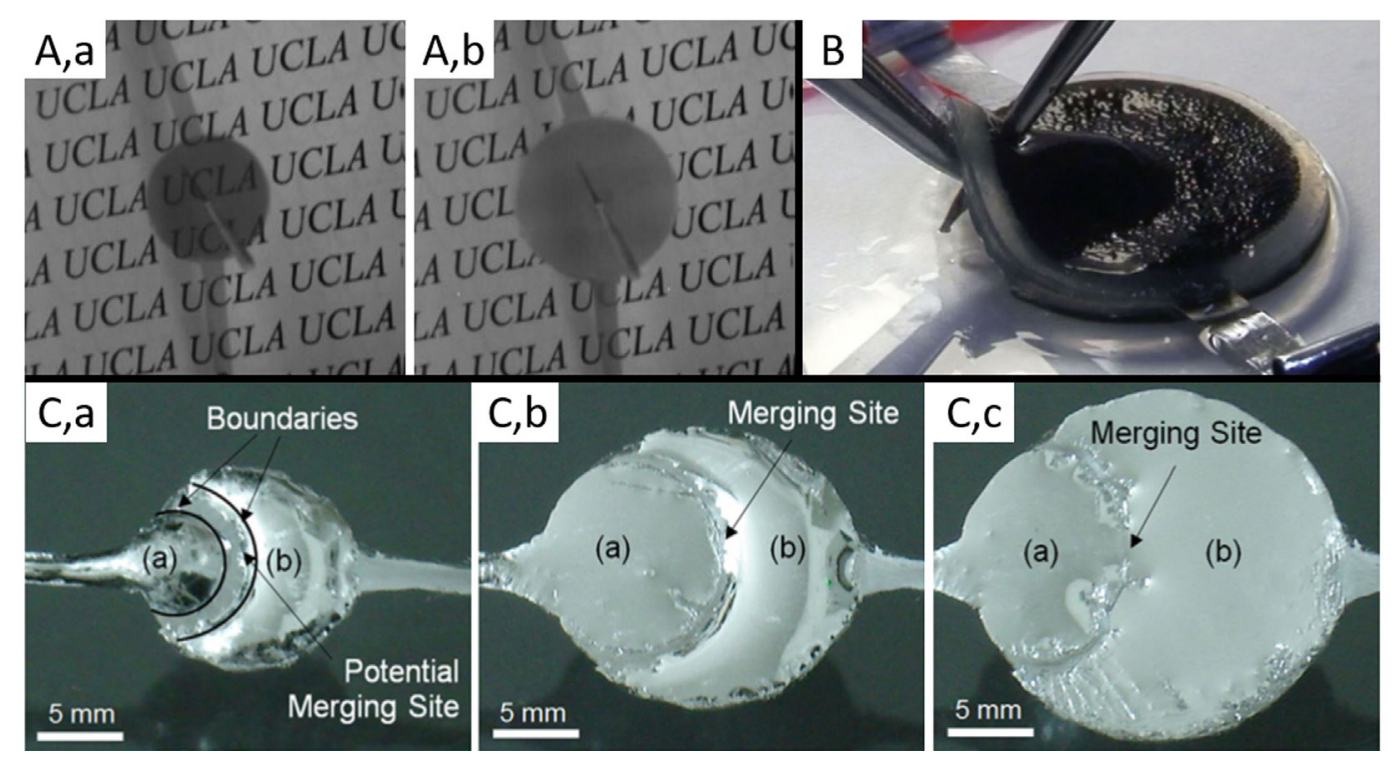

FIGURE 1 | (A) A damage resilient dielectric elastomer actuator (DEA) (via self-clearing carbon nanotube electrodes) is pierced with a foreign object [(A), a] and can still actuate [(A), b]. (B) A self-healing, silicone oil-based DEA is pierced with a needle. (C) Liquid-metal alloy is used as a self-repairing electrode layer in a DEA. [(C), a] The electrode is completely severed into two parts via separation of the liquid alloy. [(C), b] Upon application of the high voltage, the active side (a) expands, but the disconnected side does not (b). [(C), c] The electric potential disparity causes the liquid metal to flow from the active side to the inactive side, repairing the electrode and activating the rest of the DEA. (A) Reproduced from Yuan et al. (2008), (02008 John Wiley \& Sons Inc. (B) Adapted from Hunt et al. (2014), 2014 AIP Publishing LLC. (C) Reproduced from Liu et al. (2013), (02013 AIP Publishing LLC. All figures are used with permission.

materials and dielectric materials to develop fault tolerance. In one work, a reduced-graphite electrode layer was used to achieve self-clearing (Michel et al., 2012). Although the original conductivity and stiffness of the undamaged electrode was higher than that of the CNT electrodes presented previously (Yuan et al., 2008), the electrode layer self-cleared without any increase in stiffness. In a separate work, damage resilience was embedded into the dielectric layer instead of the electrode through implementation of a chemically altered polymethylvinylsiloxane silicone. In the high heat of a spark, this dielectric material rapidly reacts to increase the local impedance, blocking further charge loss through the initial fault (Dünki et al., 2015).

\section{Self-Healing DEAs}

Moving beyond "fault tolerance," several other works introduce fully self-healing systems into DEAs. This has been done by creating both self-healing dielectric layers and electrodes. Yu et al. (2015) first demonstrated a silicone dielectric elastomer that could self-seal holes in the dielectric layer created by a high-energy discharge spark. Li et al. (2016a) developed a highly stretchable, self-healing silicone elastomer and used it as the dielectric layer in a DEA to withstand both electrical and physical damage. A flat sample of the self-healing elastomer was punctured with a hole, allowed to heal for $72 \mathrm{~h}$ at room temperature, and then used as a DEA. The damaged site experienced no dielectric breakdown, even with application of an $11-\mathrm{kV}$ charge on the electrodes. This research was followed up by Madsen et al., who presented a whole family of self-healing, stretchable dielectric silicones for use in DEAs (Madsen et al., 2016b).
Two other recent works have focused on harnessing the intrinsic healing of fluidic systems to build self-healing dielectric layers and electrodes. Hunt et al. (2014) created a dielectric layer from an open-cell silicone foam filled with silicone oil, with an electrode made out of a solidified carbon grease. When this DEA was punctured repeatedly with a needle (Figure 1B) or cut with scissors, the DEA rapidly self-healed and continued to function. Since the dielectric layer was a two-phase system, the dielectric oil flowed into the damaged sites, restoring the dielectric barrier between the two electrodes without any loss of flexibility or actuation potential in the DEA. Liu et al. used room-temperature liquid metals (the same used in self-healing electronics, see Self-Healing Electronics for Soft Robotics) to create a highly deformable thin-film fluidic electrode for a DEA (Liu et al., 2013). This liquid-metal electrode was able to self-heal from a break introduced by squeezing the liquid metal out from between two sections and sealed with the liquid metal's non-conductive oxide skin (Figure 1C, a). With simple application of the same potential used to cycle the actuator, the liquid metal mechanically bridged the electrical block, reconnecting the rest of the electrode and restoring full functionality to the DEA (Figure 1C, b,c).

Damage resilient DEAs have been demonstrated using a variety of techniques. In the context of soft robotics, however, there are still challenges to overcome. DEAs made with self-clearing electrodes often must be operated at a reduced voltage in order to maintain the viability of the DEA during cyclic use (Stoyanov et al., 2013). An electric breakdown at higher voltages can cause catastrophic failure in the elastic dielectric layer, regardless of the self-clearing electrode. Furthermore, due to limitations in prestraining and elastic response of self-healing dielecric materials 
(Hunt et al., 2014), self-healing DEAs do not experience strains as large as their non-healing, counterparts. Self-healing DEAs also take a significant amount of time to heal, compared to their self-clearing counterparts (Li et al., 2016a). In the future, damage resilient DEAs might benefit from combining the various methods employed above: self-clearing or self-repairing electrodes with self-healing dielectrics, to create fully healing, highly resilient actuation systems.

\section{Inflatable Actuators}

Pneumatic or hydraulic actuators created out of soft elastomeric silicone materials have become ubiquitous in the soft robotics community (Hughes et al., 2016; Lee et al., 2017). These actuators are made by casting the elastomer to create channels that, when inflated, cause the body to bend (or twist) in a manner dependent on the channel design. Their soft, highly deformable elastomer bodies inherently resist damage: absorbing impacts, twisting and compressive loads and more (Martinez et al., 2014), and can even survive being run over with a car (Martinez et al., 2014; Tolley et al., 2014). There is a key problem with this damage resistance: like a balloon, if the actuators pop from overpressure or puncture, they lose all functionality.

Shepherd et al. (2013) presented a potential opportunity to correct this deficiency, wherein they demonstrated a pneumatic actuator that could be punctured with a 14-gauge needle and continued to function. The molded silicone elastomer actuator was reinforced with polyaramid fibers (Kevlar) dispersed into the silicone before curing (Figure 2A). This composite pneumatic arm was punctured with a needle while under positive pressure and maintained its internal pressure, even after the needle was removed (Figure 2A, b-d). Though the reason behind the damage resilience was never fully discovered, the current theory is that the damage resilience stems from a combination of the polyaramid fibers preventing crack propagation (Geethamma et al., 2005) and the silicone's natural tendency to self-adhere when elastically returning to its original molded shape (after removal of the needle). In another recent example, Wallin et al. (2017) developed a self-healing elastomer-based soft robot, wherein UV cure elastomer resins were used to stereolithographically $3 \mathrm{D}$ print hydraulic actuators. The $3 \mathrm{D}$ printing process trapped liquid resin in the elastomer; when the robot was punctured, the excess resin was able to seal up the holes if given sufficient UV stimulus (such as direct sunlight).

Terryn et al. (2015, 2017a,b) have taken a different approach to resilient pneumatic actuators by shaping self-healing polymers into inflatable chambers. In their early work, they molded a single, thin-walled cube out of a thermally responsive self-healing polymer and demonstrated its inflation capacity, even after catastrophic failure (Terryn et al., 2015). Although the pneumatic cube was made out of a stiff polymer (when compared to elastomers), it deformed with a $40 \%$ increase in side-to-side dimension when inflated (Figure 2B, a). To test its self-healing, the cube
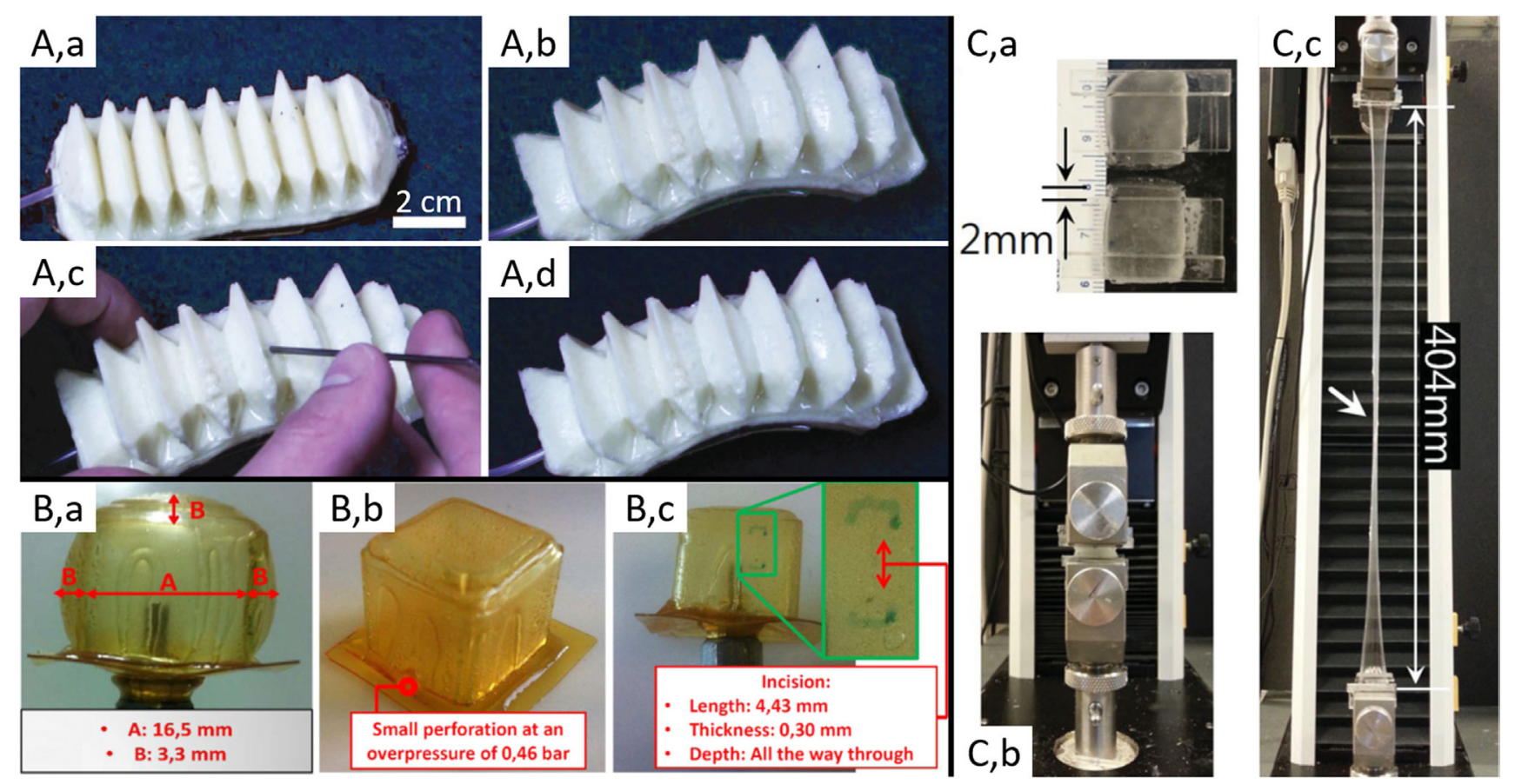

FIGURE 2 | (A) Damage resilient pneumatic actuator in an uninflated [(A), a] and inflated [(A), b] state. While inflated, the actuator is punctured with a 14-gauge needle $[(\mathbf{A}), \mathbf{c}]$, but the actuator remains capable of inflation $[(\mathbf{A}), \mathrm{d}]$. (B) First-generation prototype of a self-healing pneumatic chamber. The stiff self-healing polymer expands when inflated [(B), a], though overpressure leads to a small air leak [(B), b]. After slitting open the pneumatic chamber and allowing both the slit and the air leak to self-heal [(B), c], the chamber was capable of reinflation. (C) A rapid, self-healing, extensible hydrogel undergoing a self-healing test. The material is severed into two 2 mm segments [(C), a], allowed to self-heal for $\sim 5$ min while being mounted into a tensile machine [(C), b] and then stretched over 100 times its original length [(C), c-with the healed part emphasized by the arrow]. (A) Adapted from Shepherd et al. (2013), () 2016 John Wiley \& Sons Inc. (B) Reproduced from Terryn et al. (2015), (C) 2015 IOP Publishing Ltd. (C) Reproduced from Jeon et al. (2016), @ 2016 John Wiley \& Sons Inc. All figures are used with permission. 
was inflated with positive pressure until the chamber popped. To enhance the failure of the actuator, the cube was also cut through with a blade before being heated to instigate self-healing (Figure 2B). After undergoing this puncture and self-healing cycle, the cube inflated the same way it did before it received any damage (both in force produced and displacement achieved). Most recently, Terryn et al. (2017b) demonstrated that by patterning these cubes adjacent to one other, the extended system could be utilized as a soft robotic bending actuator capable of grasping objects. In another recent work, the researchers utilized this same self-healing material to create a pneumatically actuated artificial muscle that can contract over $10 \%$ of its length (Terryn et al., 2017a).

Inflatable actuators have seen initial forays into self-healing and damage resilience, and these initial works open possibilities for future development. For example, self-healing inflatable robots open up possibilities in actuator reconfigurability, as the inflatable actuator material can be cut and rearranged as necessary. To achieve such goals, the limitations of the state-of-the-art must be addressed, from long healing times to a need for an intense source of stimulus for self-healing. Since inflatable actuator systems have yet to show any stimuli-independent healing, it will be particularly important in future research to integrate the self-healing stimulus into the soft actuator.

\section{Hydrogel Actuators}

Hydrogels are a type of extremely hydrophilic thermoset polymer matrix that absorb water molecules into the bulk material. By pulling water molecules in between the long polymer chains, a hydrogel's polymer matrix expands, enabling a change in size many times that of the original structure. This diffusion-limited process has been used repeatedly in soft robots as a potential actuation method (Gerlach and Arndt, 2009; Richter, 2009; Kim et al., 2013). Self-healing hydrogels are their own field of research for materials scientists, as can be seen in recent reviews (Phadke et al., 2012; Taylor and Marc in het Panhuis, 2016). Yet, despite this field of research, hydrogel self-healing has yet to enter the soft robotics community, so this section is mostly forward-looking based on presently developed systems.

Responsive hydrogels have not generally been used in actuators (inflatable or otherwise) like silicones and other inert elastomers. Yuk et al. recently broke this trend in their novel application of hydrogels as an inflatable robotic gripper (Yuk et al., 2017). The hydraulic gripper was built with a highly deformable hydrogel that was simultaneously gentle and robust, capable of trapping a live fish without harming it. Highly stretchable, self-healing hydrogels such as the one recently presented by Jeon et al. (2016) could potentially be used to create these types of hydrogel grippers. Their hydrogel can self-heal very quickly (in under $30 \mathrm{~s}$, given ideal conditions) and can strain over $1,000 \%$ its original length (Figure 2C). Similar work has recently been presented by Liu and $\mathrm{Li}$ (2017) whose tough, selfhealing hydrogel requires slightly more healing time but is also ionically conductive.

There is much to gain by further exploring self-healing hydrogels in soft robots. For example, by adding hygroscopic ions to the hydrogel, the hydrogel could self-hydrate by pulling water out of the ambient environment (Bai et al., 2014; Chen et al., 2014), ensuring that the actuator is always ready to self-heal. The high water concentration in hydrogels (when compared with the humidity of the surrounding air) can enable hydrogel polymers to heal much more rapidly than normal self-healing polymers, as demonstrated by Jeon et al. (2016). However, one constant challenge that hydrogels face is ensuring that they remain sufficiently hydrated. Further advantages gained through the use of conductive hydrogels will be discussed briefly in Section "Shape Memory Materials" in the context of self-healing electronics.

\section{SELF-HEALING SOFT ROBOT STRUCTURES}

Given the goals of environmental adaptability and large degreeof-freedom operation for soft robots, it is not surprising that structure is of deep interest to soft robotic design (Bar-Cohen and Breazeal, 2003; Mazzolai et al., 2007; Case et al., 2016). Designing with materials that support actuation and sensing is crucial to enable functionality and adaptability in soft robots. Passive structures, material backbones that hold together a series of actuators and sensors, can easily be enhanced by adding selfhealing functionality (Ghosh, 2009; Li and Meng, 2015; Huynh et al., 2017). Of particular interest to soft roboticists are stiffness changing materials that enable soft robotic structures to have low stiffness for adaptation or actuation, and high stiffness to increase output forces or provide stability. A recent review covers this topic in more detail in its application to soft robotics (Manti et al., 2016). It is with this idea of structural materials that we continue our investigation of self-healing and damage resilience in soft robotics.

\section{Low Melting Temperature Materials}

Materials that have been employed in purely functional structural cases are primarily those that can undergo phase changes at low temperatures, such as low melting point alloys (LMPAs) or wax. This is because the low-temperature phase change alters the material stiffness by many orders of magnitude, with relatively small amounts of energy input. These materials are also ideal for self-healing, since they can change to a liquid form that readily flows to fill cracks, holes, or other damage. Once the system has healed the damage, the materials can be cooled again to restore a continuous solid body.

Low melting point alloys have been used in variable stiffness applications in order to provide a stiffening or morphable element in the robot (Nakai et al., 2002; Shan et al., 2013; Shintake et al., 2015), typically display melting points below $70^{\circ} \mathrm{C}$ and are solid at room temperature. Dr. Dario Floreano's lab has demonstrated the value of LMPAs as self-healing, variablestiffness soft robotic components (Figures 3A,B) (Schubert and Floreano, 2013). The researchers started by showing that the solid LMPA encapsulated in an elastomer provides structural stiffness until overloaded, causing the metal to crack and break. When this happens, the load is removed, allowing the encapsulating silicone to restore its original shape and pushing the 


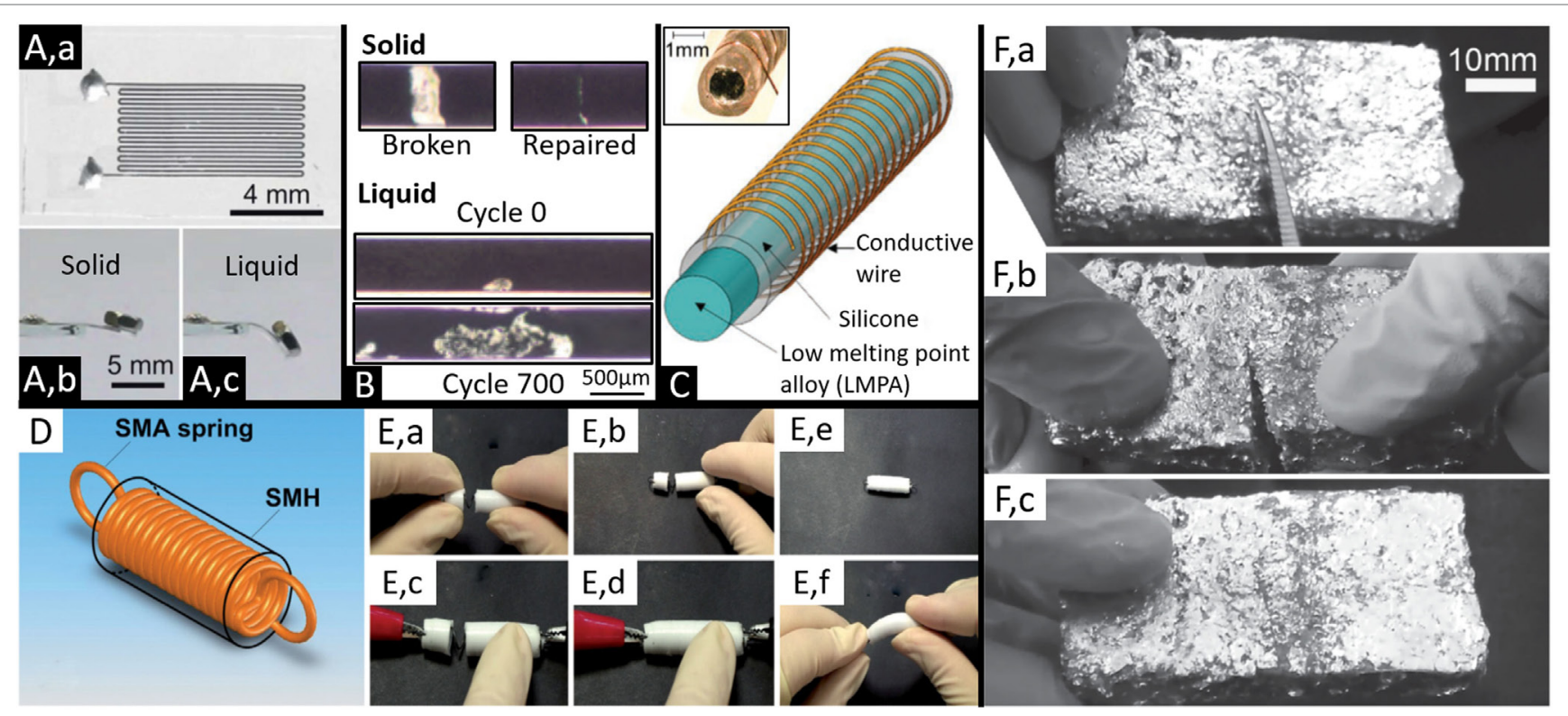

FIGURE 3 | (A) A planar variable stiffness material made of a self-healable low melting point alloy microchannel in silicone. Top view [(A), a] and side views in a stiff $[(\mathbf{A})$, b] and soft $[(\mathbf{A}), c]$ state. (B) Photographs of a low melting point alloy (LMPA) microchannel that has been fractured then Joule-heated to self-repair, as well as photographs of an LMPA microchannel in a liquid state showing degradation after 700 strain cycles. (C) Self-healing variable-stiffness fiber comprised of LMPA in a compressive silicone sleeve, with a cross section photo inset. (D) Diagram of self-healing hybrid with shape memory alloy (SMA) coils in a self-healing polymer exterior [labeled as a shape-memory hybrid (SMH)]. (E) A Self-healing cycle of the hybrid. Pulling the SMH apart [(E), a,b]; Joule heating the SMA to restore shape and encourage self-healing [(E), c,d]; the SMH after healing [(E), e] and bent to show restoration of material flexibility [(E), f]. (F) Self-healing of an LMPA-foam composite. Damaging the LMPA-foam composite with scissors [(F), a], showing the damage [(F), b] and resealing the damage [(F), c]. (A, B) Adapted from Schubert and Floreano (2013), () 2013 The Royal Society of Chemistry. (C) Adapted from Tonazzini et al. (2016), (02016 the authors. (D,E) Reproduced from Huang et al. (2010) (O2010 Elsevier Ltd. (F) Reproduced from Van Meerbeek et al. (2016), @2016 John Wiley \& Sons Inc. All figures are used with permission.

cracked metal together. By Joule-heating the metal, it melts and reforms a continuous structural system (Figure 3B). Though this process breaks down after several hundred cycles (Figure 3B), it is possible to completely replace the damaged LMPA. Later work advanced this concept by sealing LMPA into a silicone tube that was pre-stretched (see Figure 3C) (Tonazzini et al., 2016). The pre-stretched tube added a constant internal compression to the LMPA, improving the self-healing process when compared to a system using the exact same setup and materials without the pre-stretch.

Polyurethane and silicone foams have been previously used as structural elements in soft robotics, as they are usually easy to deform, compress well, and often can sustain large extensions (Shimoga and Goldenberg, 1992; Lipson, 2014; Yuen et al., 2014, 2016). By impregnating porous foams such as these with lowmelting point materials, variable stiffness materials are formed. This structure differs significantly from the above examples of encapsulated LMPA, as the low-melting point materials adhere to the foam (even in a liquid state) using capillary forces and wetting adhesion. Van Meerbeek et al. (2016) mixed LMPA into pre-cured silicone to create an open-celled, foam structure (see Figure 3F). Not only does the LMPA provide stiffening to the foam structure but also enables damage repair by welding the foam block back together with the LMPA post damage (Figure 3F, c). Mirroring the use of LMPAs, Cheng et al. (2014) filled a polyurethane foam lattice with wax which they broke repeatedly though over-compression. This foam-wax structure can self-heal back to nearly full-strength by melting the wax, even after multiple over-compressions. Although not conductive like LMPAs, wax does hold an advantage over LMPA since careful tuning of the molecular structure of the wax will separate out the softening temperature (for physical shape change) from the solid-to-liquid phase change temperature (for self-healing).

Characterization and implementation of soft robotic variablestiffness, self-healing structures has only just begun. There is much opportunity for research into structural materials that can change shape and heal from mechanical damage by phase changing and reflowing in a soft structure. Finding ways for a soft robotic system to auto-detect damage in a phase-changing structure and initiate the self-repair process is one possible future step that could be taken in this area.

\section{Shape Memory Materials}

Shape memory materials are a type of material, including both metallic shape memory alloys (SMAs) and shape memory polymers (SMPs), that can be plastically deformed from a preprogrammed state and self-return to their programmed shape upon controlled heating. SMAs and SMPs are common actuator tools that have been used frequently in soft robotics applications (Ionov, 2011; Albu-Schäffer and Bicchi, 2016; Hou, 2016; Rodrigue et al., 2017), but they have only occasionally been used as variable-stiffness structural materials (Manti et al., 2016). Their ability to autonomously restore form after plastic deformation 
parallels the motivations of self-healing and damage resilience as presented thus far. However, since their common use as actuators does not strictly fall into our definition of damage resilience (the plastic deformation is expected during operation), we will not explore this idea further.

With the common use of SMAs and SMPs as actuators, it would not be difficult to implement them as reinforcing structural elements in damage resilient soft robots (Kirkby et al., 2008; Ferreira et al., 2016). Huang et al. (2010) demonstrated the feasibility of this by embedding a coiled SMA wire inside of a semiflexible, self-healing polymer (Figures 3D,E). When the polymer structure was stretched beyond its fracture limit, the SMA coil prevented the two segments from separating completely. After failure of the encapsulating polymer, the SMA wire was Joule heated, simultaneously pressing the two fractured halves of the polymer together and heating them so that they could self-heal, thus restoring the polymer flexibility (see Figure 3E, a-f). Xiao et al. (2010) presented a self-healing SMP which could heal its surface after being scratched, which has initiated research into self-healing coatings (Luo and Mather, 2013; Dalmoro et al., 2016; Lutz et al., 2016). SMPs have also been used in two-step self-healing processes where the SMP can close whole cracks using the shape memory effect then self-heal the cracks through internal chemistry (Nji and Li, 2010, 2012; Rodriguez et al., 2011). Such hybrid systems that allow both crack closure and crack healing show much promise, though the biggest challenge will be demonstrating this capacity while simultaneously controlling the soft robot using these same materials. For more details on self-healing and shape memory materials, we highly recommend the first chapter of this book: Li and Meng (2015) or this recent review: Meng and Li (2013).

\section{SELF-HEALING ELECTRONICS FOR SOFT ROBOTICS}

For any robot to have closed-loop control, it will require some form of sensory feedback combined with an on-board computer to control its actuation. Toward this goal, sensory skins have been sought by soft roboticists as their flexibility suggest excellent integration of complex electronic components into soft-bodied robots ( $\mathrm{Lu}$ and Kim, 2014). There is an entire class of materials and devices with numerous arrays of sensors (or even actuators) designed to be either compatible with human skin so that they can adhere to a person (Kim et al., 2011), or be generally stretchable (McCoul et al., 2016). Integration of self-healing into electronics that are both flexible and stretchable is key to a fully controllable, self-healing soft robot.

A simple example of self-healing, flexible electronics comes from over a decade ago when Carlson et al. (2006) demonstrated a flexible sensor skin using standard copper-based electronics encapsulated in a self-healing polymer. The polymer body was thin enough to be flexible, but when cracked by over-bending, it could heal completely. This basic body-healing could not restore damaged electronic components; however, once the metal-based sensor was damaged, the sensor ceased to function. Since then, a recent progress report has highlighted work done in polymer chemistry and physics to develop self-healing polymers and flexible electronic components, specifically with a focus on wearables applications (Huynh et al., 2017). In it, self-healing polymers find applications in a number of sensory-skin devices such as flexion sensors (D'Elia et al., 2015), strain sensors (Wu and Chen, 2016), capacitors, supercapacitors, batteries, and solar cells (Wang et al., 2013, 2014; Sun et al., 2014, 2016; Banerjee et al., 2015; Huang et al., 2015; Zhao et al., 2016). Even though research into these devices continues, we have yet to see many integrated into soft robotic systems.

Two different approaches have been taken by researchers to develop fully self-healing, flexible (and sometimes highly stretchable) electronics implementable in soft robotics. The first uses room temperature liquid metals encapsulated in a self-healing structure, and the second uses a composite self-healing bulk polymer mixed with conductive filler.

\section{Room Temperature Liquid Metal-Based Electronics}

Gallium-based room temperature liquid metals (eutectic gallium-indium, or eGaIn, and eutectic gallium-indium-tin, or galinstan, alloys) are often used in highly stretchable and flexible soft electronics (Dickey, 2016, 2017). Their unique properties allow for a variety of soft systems to be developed that are not available in solid-metal electronics. First, when encapsulated in channels in a silicone elastomer, the liquid metal flows readily, maintaining continuity as the channel changes geometry due to external extension or compression. Furthermore, when galliumbased liquid metals are exposed to air, the liquid metal forms a stabilizing oxide layer that prevents unwanted flow (Dickey, 2014). These two properties make these alloys ideal for use in damage resilient electronics: the stabilizing oxide prevents the conductive liquid from leaking out any punctures/holes, but the liquid-like behavior allows it to seal circuit breaks.

The effectiveness of room-temperature liquid metals in damage resilient circuitry was recently demonstrated by Li et al. (2016b). In this work, liquid metal channels encapsulated in PDMS silicone were cut and pulled apart, thereby breaking the circuit (Figure 4A, a). When released, the material elastically returned to its original form and the liquid metal reconnected the electrical path (Figure 4A, b). Palleau et al. (2013) used a self-healing, stretchable polymer as an encapsulating body around a room-temperature liquid metal conductive circuit. This combination was used in both flexible self-healing wires and bulk planar materials with liquid-metal channels. The bulk planar material could mechanically and electrically self-heal after being separated into two parts (Figure 4B, a,b). Furthermore, the self-healing enabled reconfigurability in the material, as a $2 \mathrm{D}$ electronic pathway could be cut and then reconfigured into a 3D electrically conductive shape (Figure 4B, c,d). This powerful demonstration shows separate self-healing mechanisms for the bulk material and the electrical components, and how to combine the two mechanisms to create a fully selfhealing system.

Though self-healing electronics based on liquid metals have been demonstrated in their initial forms, we have yet to see integration of these demonstrations into more complex devices. 


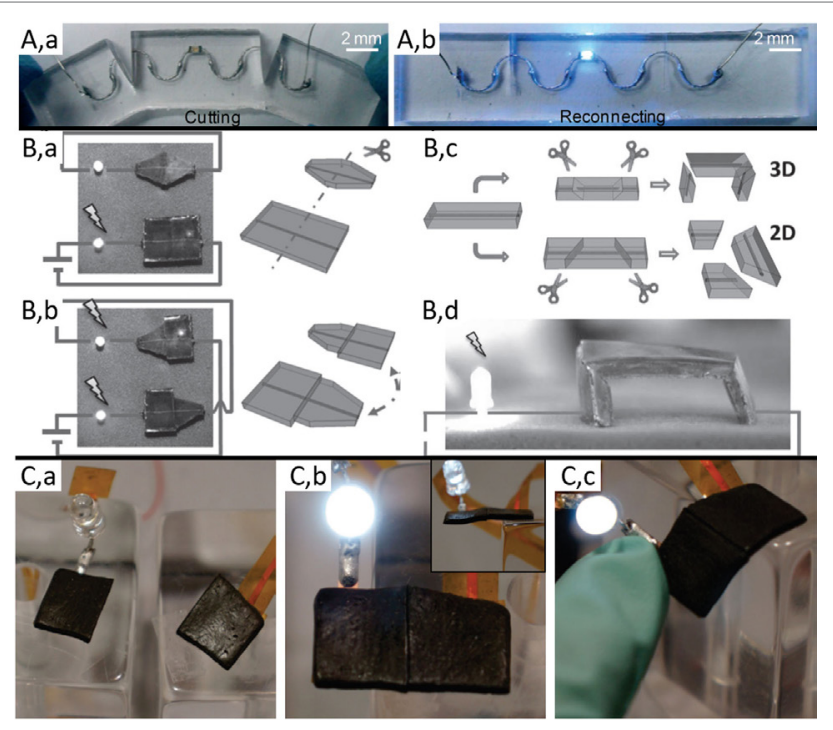

FIGURE 4 | (A) LED integration into a liquid-metal circuit. When the silicone is cut, the electrical pathway breaks, disconnecting the LED [(A), a]. When the silicone is allowed to return to its original form the liquid metal reconnects, closing the circuit [(A), b]. (B) A liquid metal circuit embedded in a self-healing polymer. After being cast into initial shapes, the polymers can be cut and healed into 2D [(B), a,b] and 3D [(B), c] shapes. If the liquid metal channel is aligned during this healing, electrical conductivity is also restored [(B), d]. (C) A conductive, flexible, self-healing polymer composite. The polymer is severed [(C), a] and then allowed to self-heal restoring electrical connectivity [(C), b]. After healing, the composite's structural integrity [(C), b inset] and flexibility are restored [(C), c]. (A) Reproduced from Li et al. (2016b), @ 2016 The Royal Society of Chemistry. (B) Reproduced from Palleau et al. (2013), (C) 2013 John Wiley \& Sons Inc. (C) Reproduced from Tee et al. (2012), @ 2012 Macmillan Publishers Limited. All figures used with permission.

One potential challenge facing this system is the non-conductive oxide layer that builds up each time the liquid metal is exposed to air (during multiple self-healing events), which results in overall decreasing conductance. However, liquid metal oxidation has also been shown to prevent the liquid metal from leaking during healing events by creating an encapsulating seal at the location of failure (Dickey, 2014). Therefore, while highly advantageous in simple applications, implementation of liquid metal as a selfhealing conductor may be limited in applications where stable conductance is necessary, such as resistive sensors.

\section{Composite Polymer Electronics}

A second approach to developing fully self-healing electronic systems uses conductive polymer composites formed out of a self-healing polymer matrix and a conductive filler. Appropriate mix ratios can allow for strong electrical conductivity through the bulk material, while maintaining the self-healing properties of the polymer bulk (Tee et al., 2012; Gong et al., 2013). Any cut or puncture in the polymer will self-heal, reconnecting the conductive filler material and rejoining the circuit, much like the material demonstrated by Tee et al. (2012) (Figure 4C). In this work, a polymer composite was demonstrated that could withstand moderate flexing and twisting (withstanding strains of up to $20 \%$ ), while also being highly conductive and self-healing. The untreated material can withstand significantly higher strains, but when sufficient conductive filler is added ( $31 \% \mathrm{vol})$ to enable high conductivity $(10 \mathrm{~S} / \mathrm{cm})$, the material's strain-to-failure is reduced. Alternatively a self-healing elastomer can be coated with a layer of conductive particles, as demonstrated by Cao et al. (2017a). As long as the conductive coating is aligned during the self-healing process, the material regains its conductivity. It is also worth noting that the elastomer presented in this work is able to self-heal in seconds (on the same order of magnitude as hydrogel self-healing, but without the need to be hydrated), which represents a step forward for self-healing elastomeric materials.

Conductive hydrogels that are self-healing at room temperature, robust, and elastically stretchable have begun to emerge in simple composite-polymer sensory applications. A common thread among recent examples is the use of metal ions as a key to both the self-healing chemistry and the conductive element (Darabi et al., 2017; Lei et al., 2017; Liu and Li, 2017; Liu et al., 2017). Though adding metal ions increases the conductivity of the hydrogels, researchers have carefully tuned the concentration: too low and the hydrogel does not conduct, too high and either the flexibility of the hydrogel is reduced or it ceases to self-heal. Cai et al. (2017) took a mixed approach by developing a self-healing, stretchable hydrogel and adding conductive filler (CNTs), much like the composite elastomers previously mentioned. This conductive hydrogel composite can self-heal in $60 \mathrm{~s}$ and recover $98 \%$ of its electrical conductivity (demonstrated multiple times on the same sample). A third approach to conductivity in self-healing, flexible hydrogels is demonstrated from previous work, wherein the polymer network itself provides the conductivity (Shi et al., 2015).

There are many challenges to overcome as conductive composite soft polymers become more incorporated into damage resilient soft robotic systems. Though the relative electrical stability of many conductive composite polymers has been demonstrated over a few strain cycles, a long-term fatigue cyclic test has yet to prove that these materials do not suffer from electrical drift. The few examples of long-term testing on ionically conductive hydrogels have shown that hydrogel systems can lose water through evaporation during use outside of a solvent environment, and when this happens, their performance drops significantly (Cai et al., 2017). Also, hydrogel composites tend to have higher resistances (greater than $1 \mathrm{k} \Omega$ for small samples), limiting their use to mostly strain sensing rather than conductive pathways. For a more comprehensive look at self-healing composite polymers (both bulk composites and conductive composites), readers are referred to these other recent, in-depth reviews/book chapters: Gibson (2010), Benight et al. (2013), Zhu et al. (2014), Ahner et al. (2015), Zhong and Post (2015), Zhang et al. (2017).

\section{FUTURE PROSPECTS AND CHALLENGES}

There are many open possibilities for the future of self-healing and damage resilience in soft robotics. Since multifunctional materials that bridge functional partitions drive innovation in the soft robotics field, it is worth pointing out how the 
self-healing materials discussed in the previous sections could continue to break down functional barriers. Recently, Cao et al. (2017b) demonstrated the use of high-resistive, ionic, self-healing hydrogels as DEA electrodes, showing how work toward improving self-healing ionic hydrogels is also improving damage resilience in soft robotic actuation. Likewise, DEAs have also been used as sensory components in soft electronics (Iskandarani and Karimi, 2012; Xu et al., 2016), so progress made toward fault-tolerant and self-healing DEAs can also be applied to soft sensors and electronics. Looking to the future, LMPAs could potentially be used in place of room-temperature liquid metals in self-healing soft electronics, thereby adding additional structural function, although simultaneously introducing the need for thermal control. Furthermore, using the mixing techniques already demonstrated in liquid metal-filled silicone foams (Kazem et al., 2017), current self-healing LMPA foams could be enhanced by replacing the non-self-healing silicone elastomer with a self-healing elastomer. These are only a few examples from the large range of applications for self-healing materials that will enhance the innovation capacity in future soft robotic systems.

Though we have presented materials and work already done by researchers in the soft robotics field, along with some of the near-future prospects, there are broad challenges that must be overcome for this field to continue to grow. While self-healing materials are prevalent in the literature, it is not always possible to simply import already-existing materials into the soft robotics community. For example, we discussed the potential of using self-healing elastomers and hydrogels in inflatable actuators (see Inflatable Actuators and Hydrogel Actuators); however, the materials that are currently available for use are not the ideal solution. Current self-healing elastomers tend to rapidly stress-relax (Li et al., 2016a), losing their ability to snap back to their original form. Despite this, immediate application of currently available materials would enable an exploration of how self-healing impacts and improves various facets of soft robotics, leading to clearer material requirements for selfhealing elastomers and encouraging research into these materials. Other challenges that must be overcome include determining the nature of interfaces between materials, especially those that may be chemically active and simplifying the synthesis of selfhealing materials for bulk applications (i.e., mass-producing these materials to enable ubiquitous implementation).

\section{REFERENCES}

Abidi, H., and Cianchetti, M. (2017). On intrinsic safety of soft robots. Front. Robot. AI 4:5. doi:10.3389/frobt.2017.00005

Ahner, J., Bode, S., Micheel, M., Dietzek, B., and Hager, M. D. (2015). "Selfhealing functional polymeric materials," in Self-healing Materials Advances in Polymer Science, eds M. D. Hager, S. van der Zwaag, and U. S. Schubert (Cham: Springer International Publishing), 247-283. doi:10.1007/12_2015_333

Albu-Schäffer, A., and Bicchi, A. (2016). "Actuators for soft robotics," in Springer Handbook of Robotics, eds B. Siciliano and O. Khatib (Cham: Springer International Publishing), 499-530. doi:10.1007/978-3-319-32552-1_21

Amjadi, M., Kyung, K.-U., Park, I., and Sitti, M. (2016). Stretchable, skinmountable, and wearable strain sensors and their potential applications: a review. Adv. Funct. Mater. 26, 1678-1698. doi:10.1002/adfm.201504755
Regardless of the challenges being faced, exciting possibilities are on the horizon for self-healing soft robots. For example, DEA rolls and stacks are powerful actuators that are highly susceptible to premature failure from a single manufacturing defect (O'Halloran et al., 2008). Self-healing and self-correcting DEAs would no longer suffer from this fundamental flaw and provide future soft robots with hundreds of hours of high-deformation, high-strength actuation. Recent efforts have shown exciting progress using DEAs to blur the lines between soft robot logic control and actuation (Wilson et al., 2016). Blending actuation and control in fully integrated self-healing soft robotic systems may enable a new form of materials based logic where logic and actuation components can be cut apart and physically reprogrammed without any need for software, similar to other recent developments (Zhang and Soh, 2017). Furthermore, creative applications of materials that restore physical continuity could make soft robotics outperform their biological inspirations. We envision soft robots that can not only self-repair, but also leverage selfhealing to enable reconfigurability, whereby parts can be cut apart and reassembled to tune overall function or performance.

In conclusion, the work presented in this review demonstrates the exciting possibilities at the intersection of self-healing materials and soft robotics. We expect that as these research communities continue to intermix, emerging soft robots will have the ability to heal from damage, similarly to their biological inspirations. Further, this confluence of material breakthroughs and novel application will enable the next generation of reconfigurable soft robots with tunable gait, function, and body morphology, all on-demand.

\section{AUTHOR CONTRIBUTIONS}

$\mathrm{RB}$ and RK conceived of the review topic and wrote the text. $\mathrm{RB}$ gathered the citation base for the review. Both agree to be accountable for the content of the work.

\section{FUNDING}

$\mathrm{RB}$ is funded by a NASA Early Career Faculty award (Grant No. NNX14AO52G). Any opinion, findings, and conclusions or recommendations expressed in this material are those of the authors and do not necessarily reflect the views of the National Aeronautics and Space Administration.

Anderson, I. A., Gisby, T. A., McKay, T. G., O’Brien, B. M., and Calius, E. P. (2012). Multi-functional dielectric elastomer artificial muscles for soft and smart machines. J. Appl. Phys. 112, 041101. doi:10.1063/1.4740023

Bai, Y., Chen, B., Xiang, F., Zhou, J., Wang, H., and Suo, Z. (2014). Transparent hydrogel with enhanced water retention capacity by introducing highly hydratable salt. Appl. Phys. Lett. 105, 151903. doi:10.1063/1.4898189

Balasubramanian, P., D'Souza, C., and Farah, Y. (2016). A perspective for soft robotics: bio-inspired evolution in robotics. Eur. J. Adv. Eng. Technol. 3, 1-9.

Banerjee, S., Tripathy, R., Cozzens, D., Nagy, T., Keki, S., Zsuga, M., et al. (2015). Photoinduced smart, self-healing polymer sealant for photovoltaics. ACS Appl. Mater. Interfaces 7, 2064-2072. doi:10.1021/am508096c

Bar-Cohen, Y., and Breazeal, C. (2003). Biologically Inspired Intelligent Robots. San Diego: International Society for Optics and Photonics, 14-21. doi:10.1117/12.484379 
Bauer, S., Bauer-Gogonea, S., Graz, I., Kaltenbrunner, M., Keplinger, C., and Schwödiauer, R. (2014). 25th Anniversary Article: a soft future: from robots and sensor skin to energy harvesters. Adv. Mater. 26, 149-162. doi:10.1002/ adma.201303349

Benight, S. J., Wang, C., Tok, J. B. H., and Bao, Z. (2013). Stretchable and selfhealing polymers and devices for electronic skin. Prog. Polym. Sci. 38, 1961-1977. doi:10.1016/j.progpolymsci.2013.08.001

Brochu, P., and Pei, Q. (2010). Advances in dielectric elastomers for actuators and artificial muscles. Macromol. Rapid Commun. 31, 10-36. doi:10.1002/ marc. 200900425

Cai, G., Wang, J., Qian, K., Chen, J., Li, S., and Lee, P. S. (2017). Extremely stretchable strain sensors based on conductive self-healing dynamic cross-links hydrogels for human-motion detection. Adv. Sci. 4, 1600190. doi:10.1002/ advs.201600190

Cao, J., Lu, C., Zhuang, J., Liu, M., Zhang, X., Yu, Y., et al. (2017a). Multiple hydrogen bonding enables the self-healing of sensors for human-machine interactions. Angew. Chem. Int. Ed. 56, 8795-8800. doi:10.1002/anie.201704217

Cao, Y., Morrissey, T. G., Acome, E., Allec, S. I., Wong, B. M., Keplinger, C., et al. (2017b). A transparent, self-healing, highly stretchable ionic conductor. Adv. Mater. 29, 1605099. doi:10.1002/adma.201605099

Carlson, J. A., English, J. M., and Coe, D. J. (2006). A flexible, self-healing sensor skin. Smart Mater. Struct. 15, N129. doi:10.1088/0964-1726/15/5/N05

Carpi, F. (ed.) (2016). Electromechanically Active Polymers. Cham: Springer International Publishing.

Case, J. C., White, E. L., and Kramer, R. K. (2016). Sensor enabled closed-loop bending control of soft beams. Smart Mater. Struct. 25, 045018. doi:10.1088/ 0964-1726/25/4/045018

Chen, B., Bai, Y., Xiang, F., Sun, J.-Y., Mei Chen, Y., Wang, H., et al. (2014). Stretchable and transparent hydrogels as soft conductors for dielectric elastomer actuators. J. Polym. Sci. B Polym. Phys. 52, 1055-1060. doi:10.1002/polb.23529

Cheng, N. G., Gopinath, A., Wang, L., Iagnemma, K., and Hosoi, A. E. (2014). Thermally tunable, self-healing composites for soft robotic applications. Macromol. Mater. Eng. 299, 1279-1284. doi:10.1002/mame.201400017

Choi, H. R., Jung, K. M., Koo, J. C., and Nam, J. D. (2007). "Robotic applications of artificial muscle actuators," in Electroactive Polymers for Robotic Applications, eds K. J. Kim and S. Tadokoro (London: Springer), 49-90.

Dalmoro, V., Santos, C., and dos Santos, J. H. Z. (2016). "Smart coatings for corrosion protection," in Industrial Applications for Intelligent Polymers and Coatings, eds M. Hosseini and A. S. H. Makhlouf (Cham: Springer International Publishing), 417-435. doi:10.1007/978-3-319-26893-4_20

Darabi, M. A., Khosrozadeh, A., Mbeleck, R., Liu, Y., Chang, Q., Jiang, J., et al. (2017). Skin-inspired multifunctional autonomic-intrinsic conductive self-healing hydrogels with pressure sensitivity, stretchability, and $3 \mathrm{D}$ printability. Adv. Mater. 29, 1700533. doi:10.1002/adma.201700533

D’Elia, E., Barg, S., Ni, N., Rocha, V. G., and Saiz, E. (2015). Self-healing graphenebased composites with sensing capabilities. Adv. Mater. 27, 4788-4794. doi:10.1002/adma.201501653

Dickey, M. D. (2014). Emerging applications of liquid metals featuring surface oxides. ACS Appl. Mater. Interfaces 6, 18369-18379. doi:10.1021/am5043017

Dickey, M. D. (2016). "Liquid metals for soft and stretchable electronics," in Stretchable Bioelectronics for Medical Devices and Systems Microsystems and Nanosystems, eds J. A. Rogers, R. Ghaffari, and D.-H. Kim (Cham: Springer International Publishing), 3-30. doi:10.1007/978-3-319-28694-5_1

Dickey, M. D. (2017). Stretchable and soft electronics using liquid metals. Adv. Mater. 29, 1606425. doi:10.1002/adma.201606425

Dünki, S. J., Ko, Y. S., Nüesch, F. A., and Opris, D. M. (2015). Self-repairable, high permittivity dielectric elastomers with large actuation strains at low electric fields. Adv. Funct. Mater. 25, 2467-2475. doi:10.1002/adfm. 201500077

Ferreira, A. D. B. L., Nóvoa, P. R. O., and Marques, A. T. (2016). Multifunctional material systems: a state-of-the-art review. Comp. Struct. 151, 3-35. doi:10.1016/j. compstruct.2016.01.028

Frei, R., McWilliam, R., Derrick, B., Purvis, A., Tiwari, A., and Serugendo, G. D. M. (2013). Self-healing and self-repairing technologies. Int. J. Adv. Manuf. Technol. 69, 1033-1061. doi:10.1007/s00170-013-5070-2

Geethamma, V. G., Kalaprasad, G., Groeninckx, G., and Thomas, S. (2005). Dynamic mechanical behavior of short coir fiber reinforced natural rubber composites. Compos. Part A. Appl. Sci. Manuf. 36, 1499-1506. doi:10.1016/j. compositesa.2005.03.004
Gerlach, G., and Arndt, K.-F. (eds) (2009). Hydrogel Sensors and Actuators. Heidelberg: Springer.

Ghosh, S. K. (2009). Self-healing Materials: Fundamentals, Design Strategies, and Applications. Weinheim: John Wiley \& Sons.

Gibson, R. F. (2010). A review of recent research on mechanics of multifunctional composite materials and structures. Comp. Struct. 92, 2793-2810. doi:10.1016/j. compstruct.2010.05.003

Gong, C., Liang, J., Hu, W., Niu, X., Ma, S., Hahn, H. T., et al. (2013). A healable, semitransparent silver nanowire-polymer composite conductor. Adv. Mater. 25, 4186-4191. doi:10.1002/adma.201301069

Gu, G.-Y., Zhu, J., Zhu, L.-M., and Zhu, X. (2017). A survey on dielectric elastomer actuators for soft robots. Bioinspir. Biomim. 12, 011003. doi:10.1088/ 1748-3190/12/1/011003

Hager, M. D., Greil, P., Leyens, C., van der Zwaag, S., and Schubert, U. S. (2010). Selfhealing materials. Adv. Mater. 22, 5424-5430. doi:10.1002/adma.201003036

Hager, M. D., Zwaag, S., van der Schubert, U. S., and AbdolahZadeh, M. (eds) (2016). Self-healing Materials. Cham, Heidelberg, New York, Dordrecht, London: Springer.

Hammock, M. L., Chortos, A., Tee, B. C.-K., Tok, J. B.-H., and Bao, Z. (2013). 25th Anniversary Article: the evolution of electronic skin (E-Skin): a brief history, design considerations, and recent progress. Adv. Mater. 25, 5997-6038. doi:10.1002/adma.201302240

Hines, L., Petersen, K., Lum, G. Z., and Sitti, M. (2017). Soft actuators for smallscale robotics. Adv. Mater. 29, 1603483. doi:10.1002/adma.201603483

Hou, X. (ed.) (2016). Design, Fabrication, Properties and Applications of Smart and Advanced Materials. New York: CRC Press.

Huang, W. M., Ding, Z., Wang, C. C., Wei, J., Zhao, Y., and Purnawali, H. (2010). Shape memory materials. Mater. Today 13, 54-61. doi:10.1016/ S1369-7021(10)70128-0

Huang, Y., Huang, Y., Zhu, M., Meng, W., Pei, Z., Liu, C., et al. (2015). Magneticassisted, self-healable, yarn-based supercapacitor. ACS Nano 9, 6242-6251. doi:10.1021/acsnano.5b01602

Hughes, J., Culha, U., Giardina, F., Guenther, F., Rosendo, A., and Iida, F. (2016). Soft manipulators and grippers: a review. Front. Robot. AI 3:69. doi:10.3389/ frobt.2016.00069

Hunt, S., McKay, T. G., and Anderson, I. A. (2014). A self-healing dielectric elastomer actuator. Appl. Phys. Lett. 104, 113701. doi:10.1063/1.4869294

Huynh, T.-P., Sonar, P., and Haick, H. (2017). Advanced materials for use in soft self-healing devices. Adv. Mater. 29, 1604973. doi:10.1002/adma.201604973

Ionov, L. (2011). Soft microorigami: self-folding polymer films. Soft Matter 7, 6786-6791. doi:10.1039/C1SM05476G

Iskandarani, Y., and Karimi, H. R. (2012). Sensing capabilities based on dielectric electro active polymers - feasibility and potential state-of-the-art application. IEEE Sens. J. 12, 2616-2624. doi:10.1109/JSEN.2012.2197198

Jeon, I., Cui, J., Illeperuma, W. R. K., Aizenberg, J., and Vlassak, J. J. (2016). Extremely stretchable and fast self-healing hydrogels. Adv. Mater. 28, 4678-4683. doi:10.1002/adma.201600480

Kazem, N., Hellebrekers, T., and Majidi, C. (2017). Soft multifunctional composites and emulsions with liquid metals. Adv. Mater. 29, 1605985. doi:10.1002/ adma.201605985

Kim, D.-H., Lu, N., Ma, R., Kim, Y.-S., Kim, R.-H., Wang, S., et al. (2011). Epidermal electronics. Science 333, 838-843. doi:10.1126/science.1206157

Kim, S., Laschi, C., and Trimmer, B. (2013). Soft robotics: a bioinspired evolution in robotics. Trends Biotechnol. 31, 287-294. doi:10.1016/j.tibtech.2013. 03.002

Kirkby, E. L., Rule, J. D., Michaud, V. J., Sottos, N. R., White, S. R., and Månson, J.-A. E. (2008). Embedded shape-memory alloy wires for improved performance of self-healing polymers. Adv. Funct. Mater. 18, 2253-2260. doi:10.1002/adfm. 200701208

Kofod, G. (2008). Dielectric elastomer actuators. J. Phys. D Appl. Phys. 41, 215405-215411. doi:10.1088/0022-3727/41/21/215405

Kornbluh, R., Heydt, R., and Pelrine, R. (2009). "Dielectric elastomer actuators: fundamentals," in Biomedical Applications of Electroactive Polymer Actuators, eds F. Carpi and E. Smela (John Wiley \& Sons, Ltd), 385-393. Available at: http://onlinelibrary.wiley.com/doi/10.1002/9780470744697.ch20/summary

Kuhl, N., Bode, S., Hager, M. D., and Schubert, U. S. (2015). "Self-healing polymers based on reversible covalent bonds," in Self-healing Materials Advances in Polymer Science, eds M. D. Hager, S. van der Zwaag, and U. S. Schubert (Cham: Springer International Publishing), 1-58. doi:10.1007/12_2015_336 
Laschi, C., and Cianchetti, M. (2014). Soft robotics: new perspectives for robot bodyware and control. Front. Bioeng. Biotechnol. 2:3. doi:10.3389/fbioe.2014. 00003

Lee, C., Kim, M., Kim, Y. J., Hong, N., Ryu, S., Kim, H. J., et al. (2017). Soft robot review. Int. J. Control Autom. Syst. 15, 3-15. doi:10.1007/s12555-0160462-3

Lei, Z., Wang, Q., Sun, S., Zhu, W., and Wu, P. (2017). A bioinspired mineral hydrogel as a self-healable, mechanically adaptable ionic skin for highly sensitive pressure sensing. Adv. Mater. 29, 1700321. doi:10.1002/adma.201700321

Li, C.-H., Wang, C., Keplinger, C., Zuo, J.-L., Jin, L., Sun, Y., et al. (2016a). A highly stretchable autonomous self-healing elastomer. Nat. Chem. 8, 618-624. doi:10.1038/nchem. 2492

Li, G., Wu, X., and Lee, D.-W. (2016b). A Galinstan-based inkjet printing system for highly stretchable electronics with self-healing capability. Lab. Chip 16, 1366-1373. doi:10.1039/C6LC00046K

Li, G., and Meng, H. (eds) (2015). Recent Advances in Smart Self-Healing Polymers and Composites. Amsterdam: Elsevier/WP, Woodhead Publishing.

Lipson, H. (2014). Challenges and opportunities for design, simulation, and fabrication of soft robots. Soft Robot. 1, 21-27. doi:10.1089/soro.2013.0007

Liu, S., and Li, L. (2017). Ultra-stretchable and self-healing double network hydrogel for 3D printing and strain sensor. ACS Appl. Mater. Interfaces. 9, 26429-26437. doi:10.1021/acsami.7b07445

Liu, Y., Gao, M., Mei, S., Han, Y., and Liu, J. (2013). Ultra-compliant liquid metal electrodes with in-plane self-healing capability for dielectric elastomer actuators. Appl. Phys. Lett. 103, 064101. doi:10.1063/1.4817977

Liu, Y.-J., Cao, W.-T., Ma, M.-G., and Wan, P. (2017). Ultrasensitive wearable soft strain sensors of conductive, self-healing, and elastic hydrogels with synergistic "Soft and Hard" hybrid networks. ACS Appl. Mater. Interfaces. 9, 25559-25570. doi:10.1021/acsami.7b07639

Lu, N., and Kim, D.-H. (2014). Flexible and stretchable electronics paving the way for soft robotics. Soft Robot. 1, 53-62. doi:10.1089/soro.2013.0005

Luo, X., and Mather, P. T. (2013). Shape memory assisted self-healing coating. ACS Macro Lett. 2, 152-156. doi:10.1021/mz400017x

Lutz, A., van den Berg, O., Wielant, J., De Graeve, I., and Terryn, H. (2016). A multiple-action self-healing coating. Front. Mater. 2:73. doi:10.3389/fmats. 2015.00073

Madden, J. D. W., Vandesteeg, N. A., Anquetil, P. A., Madden, P. G. A., Takshi, A., Pytel, R. Z., et al. (2004). Artificial muscle technology: physical principles and naval prospects. IEEE J. Oceanic Eng. 29, 706-728. doi:10.1109/JOE.2004. 833135

Madsen, F. B., Daugaard, A. E., Hvilsted, S., and Skov, A. L. (2016a). The current state of silicone-based dielectric elastomer transducers. Macromol. Rapid Commun. 37, 378-413. doi:10.1002/marc.201500576

Madsen, F. B., Yu, L., and Skov, A. L. (2016b). Self-healing, high-permittivity silicone dielectric elastomer. ACS Macro Lett. 5, 1196-1200. doi:10.1021/ acsmacrolett.6b00662

Majidi, C. (2013). Soft robotics: a perspective-current trends and prospects for the future. Soft Robot. 1, 5-11. doi:10.1089/soro.2013.0001

Manti, M., Cacucciolo, V., and Cianchetti, M. (2016). Stiffening in soft robotics: a review of the state of the art. IEEE Robot. Autom. Mag. 23, 93-106. doi:10.1109/ MRA.2016.2582718

Martinez, R. V., Glavan, A. C., Keplinger, C., Oyetibo, A. I., and Whitesides, G. M. (2014). Soft actuators and robots that are resistant to mechanical damage. Adv. Funct. Mater. 24, 3003-3010. doi:10.1002/adfm.201303676

Mazzolai, B., Laschi, C., Cianchetti, M., Patane, F., Bassi-Luciani, L., Izzo, I., et al. (2007). "Biorobotic investigation on the muscle structure of an octopus tentacle," in 2007 29th Annual International Conference of the IEEE Engineering in Medicine and Biology Society (Lyon: IEEE), 1471-1474. doi:10.1109/ IEMBS.2007.4352578

McCoul, D., Hu, W., Gao, M., Mehta, V., and Pei, Q. (2016). Recent advances in stretchable and transparent electronic materials. Adv. Electron. Mater. 2, 1500407. doi:10.1002/aelm.201500407

Meng, H., and Li, G. (2013). A review of stimuli-responsive shape memory polymer composites. Polymer 54, 2199-2221. doi:10.1016/j.polymer.2013.02.023

Michel, S., Chu, B. T. T., Grimm, S., Nüesch, F. A., Borgschulte, A., and Opris, D. M. (2012). Self-healing electrodes for dielectric elastomer actuators. J. Mater. Chem. 22, 20736-20741. doi:10.1039/C2JM32228E

Murphy, E. B., and Wudl, F. (2010). The world of smart healable materials. Prog. Polym. Sci. 35, 223-251. doi:10.1016/j.progpolymsci.2009.10.006
Naficy, S., Spinks, G. M., and Baughman, R. H. (2016). "Bio-inspired polymer artificial muscles," in Bio-Inspired Polymers, eds N. Bruns and A. F. M. Kilbinger (Cambridge: Royal Society of Chemistry), 429-459. doi:10.1039/ 9781782626664-00429

Nakai, H., Kuniyoshi, Y., Inaba, M., and Inoue, H. (2002). "Metamorphic robot made of low melting point alloy," in IEEE/RSJ International Conference on Intelligent Robots and Systems (Lausanne: IEEE), Vol. 2, 2025-2030. doi:10.1109/IRDS.2002.1044053

Nji, J., and Li, G. (2010). A biomimic shape memory polymer based self-healing particulate composite. Polymer 51, 6021-6029. doi:10.1016/j.polymer.2010. 10.021

Nji, J., and Li, G. (2012). Damage healing ability of a shape-memory-polymerbased particulate composite with small thermoplastic contents. Smart Mater. Struct. 21, 025011. doi:10.1088/0964-1726/21/2/025011

O'Halloran, A., O'Malley, F., and McHugh, P. (2008). A review on dielectric elastomer actuators, technology, applications, and challenges. J. Appl. Phys. 104, 071101. doi:10.1063/1.2981642

Palleau, E., Reece, S., Desai, S. C., Smith, M. E., and Dickey, M. D. (2013). Self-healing stretchable wires for reconfigurable circuit wiring and 3D microfluidics. Adv. Mater. 25, 1589-1592. doi:10.1002/adma.201203921

Pfeifer, R., Lungarella, M., and Iida, F. (2012). The challenges ahead for bio-inspired "soft" robotics. Commun. ACM 55, 76-87. doi:10.1145/2366316.2366335

Phadke, A., Zhang, C., Arman, B., Hsu, C.-C., Mashelkar, R. A., Lele, A. K., et al. (2012). Rapid self-healing hydrogels. PNAS 109, 4383-4388. doi:10.1073/ pnas. 1201122109

Richter, A. (2009). "Hydrogels for actuators," in Hydrogel Sensors and Actuators Springer Series on Chemical Sensors and Biosensors, eds G. Gerlach and K.-F. Arndt (Berlin, Heidelberg: Springer), 221-248.

Rodrigue, H., Wang, W., Han, M.-W., Kim, T. J. Y., and Ahn, S.-H. (2017). An overview of shape memory alloy-coupled actuators and robots. Soft Robot. 4, 3-15. doi:10.1089/soro.2016.0008

Rodriguez, E. D., Luo, X., and Mather, P. T. (2011). Linear/network poly( $\varepsilon$ caprolactone) blends exhibiting shape memory assisted self-healing (SMASH). ACS Appl. Mater. Interfaces 3, 152-161. doi:10.1021/am101012c

Romasanta, L. J., Lopez-Manchado, M. A., and Verdejo, R. (2015). Increasing the performance of dielectric elastomer actuators: a review from the materials perspective. Prog. Polym. Sci. 51, 188-211. doi:10.1016/j.progpolymsci.2015. 08.002

Rosset, S., and Shea, H. R. (2012). Flexible and stretchable electrodes for dielectric elastomer actuators. Appl. Phys. A 110,281-307. doi:10.1007/s00339-012-7402-8

Roy, N., Bruchmann, B., and Lehn, J.-M. (2015). DYNAMERS: dynamic polymers as self-healing materials. Chem. Soc. Rev. 44, 3786-3807. doi:10.1039/ C5CS00194C

Rus, D., and Tolley, M. T. (2015). Design, fabrication and control of soft robots. Nature 521, 467-475. doi:10.1038/nature14543

Schubert, B. E., and Floreano, D. (2013). Variable stiffness material based on rigid low-melting-point-alloy microstructures embedded in soft poly(dimethylsiloxane) (PDMS). RSC Adv. 3, 24671-24679. doi:10.1039/C3RA44412K

Shan, W., Lu, T., and Majidi, C. (2013). Soft-matter composites with electrically tunable elastic rigidity. Smart Mater. Struct. 22, 085005. doi:10.1088/ 0964-1726/22/8/085005

Shepherd, R. F., Stokes, A. A., Nunes, R. M. D., and Whitesides, G. M. (2013). Soft machines that are resistant to puncture and that self seal. Adv. Mater. 25, 6709-6713. doi:10.1002/adma.201303175

Shi, Y., Wang, M., Ma, C., Wang, Y., Li, X., and Yu, G. (2015). A conductive self-healing hybrid gel enabled by metal-ligand supramolecule and nanostructured conductive polymer. Nano Lett. 15, 6276-6281. doi:10.1021/acs. nanolett.5b03069

Shimoga, K. B., and Goldenberg, A. A. (1992). "Soft materials for robotic fingers," in Proceedings 1992 IEEE International Conference on Robotics and Automation (Nice: IEEE), Vol. 2, 1300-1305. doi:10.1109/ROBOT.1992.220069

Shintake, J., Schubert, B., Rosset, S., Shea, H., and Floreano, D. (2015). "Variable stiffness actuator for soft robotics using dielectric elastomer and low-meltingpoint alloy," in 2015 IEEE/RSJ International Conference on Intelligent Robots and Systems (IROS) (Hamburg: IEEE), 1097-1102.

Stoyanov, H., Brochu, P., Niu, X., Lai, C., Yun, S., and Pei, Q. (2013). Long lifetime, fault-tolerant freestanding actuators based on a silicone dielectric elastomer and self-clearing carbon nanotube compliant electrodes. RSC Adv. 3, 2272-2278. doi:10.1039/C2RA22380E 
Sun, H., You, X., Jiang, Y., Guan, G., Fang, X., Deng, J., et al. (2014). Self-healable electrically conducting wires for wearable microelectronics. Angew. Chem. Int. Ed. 53, 9526-9531. doi:10.1002/anie.201405145

Sun, Y., Lopez, J., Lee, H.-W., Liu, N., Zheng, G., Wu, C.-L., et al. (2016). A stretchable graphitic carbon/Si anode enabled by conformal coating of a self-healing elastic polymer. Adv. Mater. 28, 2455-2461. doi:10.1002/adma. 201504723

Taylor, D. L., and Marc in het Panhuis. (2016). Self-healing hydrogels. Adv. Mater. 28, 9060-9093. doi:10.1002/adma.201601613

Tee, B. C.-K., Wang, C., Allen, R., and Bao, Z. (2012). An electrically and mechanically self-healing composite with pressure- and flexion-sensitive properties for electronic skin applications. Nat. Nanotechnol. 7, 825-832. doi:10.1038/ nnano.2012.192

Terryn, S., Brancart, J., Lefeber, D., Assche, G. V., and Vanderborght, B. (2017a). A pneumatic artificial muscle manufactured out of self-healing polymers that can repair macroscopic damages. IEEE Robot. Autom. Lett. 3, 16-21. doi:10.1109/LRA.2017.2724140

Terryn, S., Brancart, J., Lefeber, D., Assche, G. V., and Vanderborght, B. (2017b). Self-healing soft pneumatic robots. Sci. Robot. 2, eaan4268. doi:10.1126/ scirobotics.aan 4268

Terryn, S., Mathijssen, G., Brancart, J., Lefeber, D., Assche, G. V., and Vanderborght, B. (2015). Development of a self-healing soft pneumatic actuator: a first concept. Bioinspir. Biomim. 10, 046007. doi:10.1088/1748-3190/10/4/ 046007

Tolley, M. T., Shepherd, R. F., Mosadegh, B., Galloway, K. C., Wehner, M., Karpelson, M., et al. (2014). A resilient, untethered soft robot. Soft Robot. 1, 213-223. doi:10.1089/soro.2014.0008

Tonazzini, A., Mintchev, S., Schubert, B., Mazzolai, B., Shintake, J., and Floreano, D. (2016). Variable stiffness fiber with self-healing capability. $A d v$. Mater. 28, 10142-10148. doi:10.1002/adma.201602580

Van Meerbeek, I. M., Mac Murray, B. C., Kim, J. W., Robinson, S. S., Zou, P. X., Silberstein, M. N., et al. (2016). Morphing metal and elastomer bicontinuous foams for reversible stiffness, shape memory, and self-healing soft machines. Adv. Mater. 28, 2801-2806. doi:10.1002/adma.201505991

Wallin, T. J., Pikul, J. H., Bodkhe, S., Peele, B. N., Murray, B. C. M., Therriault, D., et al. (2017). Click chemistry stereolithography for soft robots that self-heal. J. Mater. Chem. B. 5, 6249-6255. doi:10.1039/C7TB01605K

Wang, C., Wu, H., Chen, Z., McDowell, M. T., Cui, Y., and Bao, Z. (2013). Self-healing chemistry enables the stable operation of silicon microparticle anodes for high-energy lithium-ion batteries. Nat. Chem. 5, 1042-1048. doi: $10.1038 /$ nchem. 1802

Wang, H., Ma, X., and Hao, Y. (2017). Electronic devices for human-machine interfaces. Adv. Mater. Interfaces. 4, 1600709. doi:10.1002/admi.201600709

Wang, H., and Qu, S. (2016). Constitutive models of artificial muscles: a review. J. Zhejiang Univ. Sci. A 17, 22-36. doi:10.1631/jzus.A1500207

Wang, H., Zhu, B., Jiang, W., Yang, Y., Leow, W. R., Wang, H., et al. (2014). A mechanically and electrically self-healing supercapacitor. Adv. Mater. 26, 3638-3643. doi:10.1002/adma.201305682

Wilson, K. E., Henke, E.-F. M., Slipher, G. A., and Anderson, I. A. (2016). Rubbery logic gates. Extreme Mech. Lett. 9(Part 1), 188-194. doi:10.1016/j.eml. 2016.07.001

Wool, R. P. (2008). Self-healing materials: a review. Soft Matter 4, 400-418. doi:10.1039/B711716G

Wu, D. Y., Meure, S., and Solomon, D. (2008). Self-healing polymeric materials: a review of recent developments. Prog. Polym. Sci. 33, 479-522. doi:10.1016/j. progpolymsci.2008.02.001

Wu, T., and Chen, B. (2016). A mechanically and electrically self-healing graphite composite dough for stencil-printable stretchable conductors. J. Mater. Chem. C 4, 4150-4154. doi:10.1039/C6TC01052K

Xiao, X., Xie, T., and Cheng, Y.-T. (2010). Self-healable graphene polymer composites. J. Mater. Chem. 20, 3508-3514. doi:10.1039/C0JM00307G
Xu, D., Tairych, A., and Anderson, I. A. (2016). Where the rubber meets the hand: unlocking the sensing potential of dielectric elastomers. J. Polym. Sci. B Polym. Phys. 54, 465-472. doi:10.1002/polb.23926

Yu, L., Madsen, F. B., Hvilsted, S., and Skov, A. L. (2015). "High energy density interpenetrating networks from ionic networks and silicone," in Proceedings Volume 9430, Electroactive Polymer Actuators and Devices (EAPAD) 2015 (San Diego), 94300T. doi:10.1117/12.2082917

Yuan, W., Hu, L., Yu, Z., Lam, T., Biggs, J., Ha, S. M., et al. (2008). Faulttolerant dielectric elastomer actuators using single-walled carbon nanotube electrodes. Adv. Mater. 20, 621-625. doi:10.1002/adma.200701018

Yuan, W., Lam, T., Biggs, J., Hu, L., Yu, Z., Ha, S., et al. (2007). "New electrode materials for dielectric elastomer actuators," in Proceedings Volume 6524, Electroactive Polymer Actuators and Devices (EAPAD) 2007 (San Diego), 65240 N. doi: $10.1117 / 12.715383$

Yuan, W., Li, H., Brochu, P., Niu, X., and Pei, Q. (2010). Fault-tolerant silicone dielectric elastomers. Int. J. Smart Nano Mater. 1, 40-52. doi:10.1080/ 19475411003589905

Yuen, M., Bilodeau, R. A., and Kramer, R. (2016). Active variable stiffness fibers for multifunctional robotic fabrics. IEEE Robot. Autom. Lett. 1, 708-715. doi:10.1109/LRA.2016.2519609

Yuen, M., Cherian, A., Case, J., Seipel, J., and Kramer, R. (2014). "Conformable actuation and sensing with robotic fabric," in 2014 IEEE/RSJ International Conference on Intelligent Robots and Systems (Chicago, IL: IEEE), 580-586. doi:10.1109/IROS.2014.6942618

Yuk, H., Lin, S., Ma, C., Takaffoli, M., Fang, N. X., and Zhao, X. (2017). Hydraulic hydrogel actuators and robots optically and sonically camouflaged in water. Nat. Commun. 8, 14230. doi:10.1038/ncomms 14230

Zhang, Q., Liu, L., Pan, C., and Li, D. (2017). Review of recent achievements in self-healing conductive materials and their applications. J. Mater. Sci. 1-20. doi:10.1007/s10853-017-1388-8

Zhang, Q. M., and Serpe, M. J. (2017). Stimuli-responsive polymers for actuation. Chemphyschem. 18, 1451-1465. doi:10.1002/cphc.201601187

Zhang, X., and Soh, S. (2017). Performing logical operations with stimuliresponsive building blocks. Adv. Mater. Weinheim 29, 1606483. doi:10.1002/ adma.201606483

Zhao, Y., Wei, J., Li, H., Yan, Y., Zhou, W., Yu, D., et al. (2016). A polymer scaffold for self-healing perovskite solar cells. Nat. Commun. 7, 10228. doi:10.1038/ ncomms 10228

Zhong, N., and Post, W. (2015). Self-repair of structural and functional composites with intrinsically self-healing polymer matrices: a review. Compos. Part A. Appl. Sci. Manuf. 69, 226-239. doi:10.1016/j.compositesa.2014.11.028

Zhu, F., Zhang, C., Qian, J., and Chen, W. (2016). Mechanics of dielectric elastomers: materials, structures, and devices. J. Zhejiang Univ. Sci. A 17, 1-21. doi:10.1631/jzus.A1500125

Zhu, M., Rong, M. Z., and Zhang, M. Q. (2014). Self-healing polymeric materials towards non-structural recovery of functional properties. Polym. Int. 63, 1741-1749. doi:10.1002/pi.4723

Zurlo, G., Destrade, M., DeTommasi, D., and Puglisi, G. (2016). Catastrophic Thinning of Dielectric Elastomers. arXiv preprint arXiv:1610.03257. Available at: https://arxiv.org/abs/1610.03257

Conflict of Interest Statement: The authors declare that the research was conducted in the absence of any commercial or financial relationships that could be construed as a potential conflict of interest.

Copyright $\odot 2017$ Bilodeau and Kramer. This is an open-access article distributed under the terms of the Creative Commons Attribution License (CC BY). The use, distribution or reproduction in other forums is permitted, provided the original author(s) or licensor are credited and that the original publication in this journal is cited, in accordance with accepted academic practice. No use, distribution or reproduction is permitted which does not comply with these terms. 